\title{
PLANEJAMENTO CURRICULAR DA EDUCAÇÃO FÍSICA NO PROJETO DE CORREÇÃO DO FLUXO ESCOLAR'
}

\author{
MS. ALESSANDRA CRISTINA RAIMUNDO
}

Mestre em Educação Física pelo Programa de Pós-graduação em Educação Física da Universidade Gama Filho (PPGEF-UGF), Professora substituta do Instituto de Educação Física (IEF) da Universidade

Federal Fluminense, Professora de Educação Física da Rede Estadual de Ensino em Uberlândia

(Uberlândia - Minas Gerais - Brasil)

E-mail: alecris04@yahoo.com.br

\section{DR. SEBASTIÃO JOSUÉ VOTRE}

Professor do programa de pós-graduação Stricto Sensu em Educação Física da Universidade Gama Filho - Rio de Janeiro, Doutorado em Letras na PUC-RJ, Pesquisador e bolsista de produtividade do CNPq, Coordenador do Grupo de estudos Semiótica das atividades humanas, Coordenador do

Núcleo de Pesquisa e Pós-Graduação da UGF (Rio de Janeiro - Rio de Janeiro - Brasil)

E-mail: sebastianovotre@yahoo.com

\section{DR ${ }^{\mathrm{a}}$. DINAH VASCONCELLOS TERRA}

Professora da Universidade Federal Fluminense Niterói- Rio de Janeiro, Doutorado em Ciências da Educação - Universidade de Barcelona - Espanha, Coordenadora do Grupo de Estudos em Educação Física Escolar e Formação Profissional (IEF/UFF/CNPq)

(Rio de Janeiro - Rio de Janeiro - Brasil)

E-mail: dv.terra@terra.com.br

\section{RESUMO}

Em Minas Gerais, o projeto Acelerar para Vencer vem sendo executado com vistas a oferecer estratégias de intervenção pedagógica para alunos com atraso escolar. Neste artigo, analisamos criticamente o planejamento curricular da Educação Física com a finalidade de identificar sua organização e práticas pedagógicas nesse projeto. O referencial analítico utilizado para a compreensão desta política educacional está apoiado no ciclo de políticas educacionais de Stephen Ball e Richard Bowe (1 992) apud Mainardes (2006). O corpus se constitui dos documentos das diretrizes curriculares do projeto e do planejamento do professor. Concluímos que o planejamento não expressa, de fato, como a Educação Física contribui no desenvolvimento do projeto, que pretende diminuir desigualdades escolares.

PALAVRAS-CHAVE: Política educacional; educação física; projeto acelerar para vencer; planejamento curricular.

I. O presente artigo contou com apoio financeiro sob a forma de bolsa de mestrado do CNPq. 
Este artigo é um recorte de pesquisa maior, desenvolvida numa escola pública estadual de Minas Gerais, intitulada "A educação física no Projeto Acelerar para Vencer na rede estadual de ensino na cidade de Uberlândia/MG", com o objetivo de analisar o impacto da educação física nesse projeto. Abordaremos aqui uma das categorias de análise, denominada "Planejamento curricular da educação física: dilemas e perspectivas".

A pesquisa é um estudo de caso de natureza qualitativa crítica que, segundo André (2002), trata de descrever e analisar um fenômeno social, neste caso, a Educação Física no Projeto de Correção de Fluxo Escolar. Em se tratando da análise de manifestação de uma política pública, este tipo de metodologia possibilita revelar crenças e valores de diferentes olhares e interpretações, orientando a descrição e interpretação desses fenômenos (LATORRE et al., 1997).

\section{PARTICIPANTES DO ESTUDO}

Para este estudo a escolha dos participantes ocorreu a partir dos seguintes critérios: escolas indicadas pela coordenadora regional do PAV que obtiveram êxito e aquelas com dificuldades na implementação do projeto no ano de 2009 e aceitação voluntária dos professores. Foram indicadas cinco escolas com este perfil. Após o contato com os professores, somente dois aceitaram participar da pesquisa. Utilizaremos depoimentos de um professor, ${ }^{2}$ no caso deste artigo.

O professor participante do estudo tem $3 \mathrm{I}$ anos, é ex-atleta de atletismo e graduado em Educação Física desde 2005. Trabalha na escola há quatro anos, atuando no ensino fundamental ( $6^{\circ}$ ao $9^{\circ}$ ano) e no ensino médio e há dois anos no PAV. Além das aulas desenvolvidas na escola, realiza atividades extraescolares, como participação nos jogos interescolares e atividades de corrida de rua.

$\bigcirc$ interesse do professor pela profissão se manifestou quando ele cursou o magistério no ensino médio e sentiu que a escola é um espaço motivador e incentivador na construção de novas ideias. Ele tem contrato temporário, com carga horária de 20 horas aula e atua, também, como orientador de atividades físicas e personal trainer numa academia de musculação, no período da noite.

Ele aceitou o convite para participar da pesquisa e, após esclarecimentos sobre os procedimentos e objetivos do estudo, assinou um termo de Consentimento Livre e Esclarecido. A aprovação do projeto é do Comitê de Ética e Pesquisa da Universidade Gama Filho, sob protocolo n $144 / 10$.

2. O estudo foi desenvolvido no segundo semestre de 2010. 
A escola, fundada em 197I, está localizada em bairro industrial na zona norte da cidade de Uberlândia. Atende ao ensino fundamental e médio, funcionando em três turnos; é referência para o bairro, que cresceu no seu entorno.

A escola ocupa uma quadra e é constituída por três blocos, totalizando onze salas de aula e uma biblioteca; está equipada com ventiladores, banheiros, secretaria, direção e supervisão situadas a frente do portão principal, um pátio com tablado que serve de palco para as apresentações culturais e demais atividades escolares. A cozinha, com refeitório, serve em média 90 refeições ao dia para os alunos do ensino fundamental. Contém uma cantina, de gestão da própria escola, uma quadra sem cobertura e uma sala de informática. Nos corredores e nas paredes das salas não há cartazes com qualquer tipo de informação ou ilustração. Considerando a perspectiva metodológica do estudo, utilizamos como instrumentos de coleta de informações a observação, o diário de campo, a entrevista semi-estruturada e a análise documental.

Tivemos como referência a análise de conteúdo de Bardin (2009) para compreender e interpretar os dados da pesquisa, buscando ultrapassar o nível de senso comum e o subjetivismo na interpretação, para garantir vigilância crítica ante a comunicação de documentos, entrevistas e os resultados de observação (MINAYO, 2006). A análise de conteúdo, cruzando as informações dos quatros instrumentos de coleta, aponta para o tema do planejamento como um dos eixos relevantes no projeto de correção de fluxo. O objetivo deste estudo é analisar o impacto da Educação Física no projeto acelerar para vencer a partir da categoria planejamento.

\section{INTRODUÇÃO/JUSTIFICATIVA}

Os índices de repetência, evasão e abandono escolar são problemas recorrentes na história da Educação Brasileira. Estes são, também, indicadores do fracasso escolar. Existem no Brasil inúmeras pesquisas sobre a origem desse fenômeno e várias análises de políticas educacionais de regulação do fluxo escolar para a redução de repetência e abandono escolar. Este trabalho descreve e analisa como a disciplina Educação Física é desenvolvida no contexto do projeto "Acelerar para Vencer", implementado pela Secretaria de Estado de Educação de Minas Gerais (SEE/MG), que tem como objetivo reduzir as taxas de repetência.

No Estado de Minas Gerais, a partir de 1990, as reformas educacionais geraram um conjunto de dispositivos específicos, que influenciaram projetos cujo objetivo principal era eliminar ou reduzir o fracasso escolar. Em 1998, a SEE/MG implementou um programa de aceleração da aprendizagem, que se desdobrou 
em três projetos: Travessia, Acertando o Passo, A Caminho da Cidadania ${ }^{3}$ ( 1998) e em 2008 implementou o Projeto Acelerar para Vencer (PAV - 2008). O objetivo destes programas é melhorar o desempenho escolar dos alunos que apresentam dificuldades de aprendizagem e se encontram com distorção idade/série de pelo menos dois anos.

Estas medidas são decorrentes da participação do Brasil na Conferência Mundial sobre Educação para Todos, realizada em Jomtien, na Tailândia ( 1990), convocada pela Organização das Nações Unidas para a Educação, Ciência e Cultura (UNESCO), pelo Programa das Nações Unidas para o Desenvolvimento (PNUD), pelo Fundo das Nações Unidas para a Infância (UNICEF) e pelo Banco Mundial. Estes documentos apontam, consensualmente, as necessidades básicas da aprendizagem, cujo objetivo é universalizar o acesso à educação e promover a equidade; desta conferência resultaram as bases dos planos decenais de Educação para os países de maior população no mundo.

O campo de estudos destinado a analisar as políticas governamentais tem envolvido diversos especialistas da área que procuram investigar, levantar informações e coletar dados para verificar se e em que proporção as estratégias desenvolvidas são eficientes e adequadas. Ao realizarmos o mapeamento inicial da produção acadêmica nos periódicos da CAPES, encontramos duas teses e três dissertações que tematizam os programas de aceleração da aprendizagem.

Para análise da Educação Física no PAV, utilizaremos a abordagem do ciclo de políticas educacionais de Stephen Ball e Richard Bowe (1992) apud Mainardes, um modelo analítico que analisa programas e políticas educacionais desde sua formulação inicial até sua avaliação. Esta abordagem representa uma forma de pensar a trajetória de uma política. É constituída por cinco contextos: influência, produção do texto, contexto da prática, resultados/efeitos e estratégia política.

Neste estudo, empregaremos três elementos do ciclo de políticas de Ball: os contextos da influência, da produção do texto e da prática. ${ }^{4}$ Sob essa orientação, descreveremos os contextos das reformas educacionais ocorridas globalmente e seus desdobramentos nas políticas educacionais locais.

\section{CONHECIMENTO PRODUZIDO EM TESES E DISSERTAÇÕES}

Nesta breve exposição da produção acadêmica, registramos duas teses produzidas no período de 2007/2008. Iniciamos com a tese de Souza (2007),

3. "Travessia", implementado no ${ }^{\circ}$ ciclo do ensino fundamental; "Acertando o Passo", no segundo ciclo do ensino fundamental e "A Caminho da Cidadania", no ensino médio. Estes projetos foram destinados aos alunos do noturno, que concentrava alto índice de defasagem de idade/série.

4. Explicitaremos mais adiante os três contextos, que estão separados por razões didáticas e não devem ser entendidos de forma fragmentada. 
que estuda o papel e a inserção de um programa de aceleração da aprendizagem do município de Santarém-Pará. Os dados evidenciam o distanciamento entre o proclamado e o executado, apontando como desafio o redirecionamento das ações para além de um único programa. Destaca-se a necessidade de uma política que englobe as demais facetas do fracasso escolar.

Na tese de Coimbra (2008), o objetivo é investigar de que forma a política de aceleração da aprendizagem se insere no cenário das políticas educacionais mundiais, como a ideia do programa se dissemina no Estado de Santa Catarina e quais são seus efeitos na trajetória escolar dos egressos. Os resultados apontam que as demandas da nova regulação correspondem a novo estágio do capitalismo e que é possível acelerar a aprendizagem por meio da gestão flexível do currículo.

As três dissertações foram realizadas em Minas Gerais. A pesquisa de Miranda (2002) consiste na investigação da eficiência do programa de aceleração de estudos, através da análise de resultados do PROEB (Programa de Avaliação da Educação Básica) em 2000. Os resultados obtidos indicam que esse programa é uma política de mascaramento, que dá ao aluno a falsa impressão de um tratamento diferenciado, quando, na verdade, ainda está tendo um tratamento discriminatório e excludente.

Os projetos Travessia, Acertando o Passo e A Caminho da Cidadania são analisados na dissertação de Espíndola (2003), para quem os programas atingiram seu objetivo, criaram oportunidades de recuperação da defasagem escolar e contribuíram para a retomada da autoestima dos alunos, bem como para a reformulação de suas trajetórias acadêmicas e profissionais.

Partindo de uma perspectiva subjetiva e centrada no sujeito, Moraes (2009) aborda os dizeres dos alunos a respeito do processo de ensino e de aprendizagem da língua portuguesa no programa de aceleração da aprendizagem. O subsídio teórico da análise do discurso e teorizações lacanianas sobre o sujeito evidenciaram que a relação pedagógica, numa perspectiva ética, propicia ao sujeito responsabilizar-se por suas escolhas.

As pesquisas aqui relatadas não fazem referência ao componente curricular da Educação Física no contexto do programa de aceleração da aprendizagem; em vista disso, optamos por investigar as intervenções pedagógicas da Educação Física e sua contribuição neste processo.

\section{CONTEXTO DA INFLUÊNCIA}

Para Ball ( 1992) apud Mainardes (2006, p. 5I), o contexto da influência, "onde normalmente as políticas públicas são iniciadas e os discursos políticos são construídos", é o espaço em que ocorrem as disputas entre grupos de interesses e se definem as finalidades sociais da educação. Nesta perspectiva, pode-se dizer 
que o contexto da influência nas reformas educacionais, especificamente no Estado de Minas Gerais, se dissemina na perspectiva neoliberal, influenciando a definição de políticas e prioridades voltadas para a lógica do mercado.

Os discursos sobre eficiência, qualidade em educação, gestão escolar, currículo integrado e construção de competências estão presentes nas diferentes reformas educacionais executadas em diversos países, onde influenciam as políticas nacionais e a construção dos discursos. Estas políticas respondem aos compromissos firmados pelo governo brasileiro na Conferência Mundial de Educação Para Todos em Jomtien, Tailândia, em 1990 (TOMMASI, 1998). Desse encontro surgiram as ideias contidas no Plano Decenal de Educação para Todos ( $1993-2003),{ }^{5}$ os compromissos reafirmados no Plano Político Estratégico 1995- 1998 e retomados na nova Lei de Diretrizes e Bases da Educação Nacional (LDBEN).

O Plano Decenal de Educação para Todos ( 1993-2003) foi amplamente discutido e mobilizou as três esferas do governo, as entidades da sociedade civil e a participação dos estados e municípios. Segundo o Plano,

Os compromissos que o governo brasileiro assume, de garantir a satisfação das necessidades básicas de educação de seu povo, expressam-se no Plano Decenal de Educação para Todos, cujo objetivo mais amplo é assegurar, até o ano 2003, a crianças, jovens e adultos, conteúdos mínimos de aprendizagem que atendam às necessidades elementares da vida contemporânea. (BRASIL, 1993).

O Plano Político Estratégico (1995-1998) firma o compromisso assumido no Plano Decenal de Educação Para Todos e realiza esforços para expandir e melhorar a qualidade de ensino, implantando o Fundo Nacional de Manutenção e Desenvolvimento do Ensino Fundamental e Valorização do Magistério (FUNDEF). Por meio do FUNDEF, são criados mecanismos que garantem um valor mínimo de financiamento por aluno em todo o país, que estabelecem mecanismos de valorização e que exigem dos estados e municípios a formulação de planos de carreira e remuneração do magistério.

A aprovação da Lei de Diretrizes e Bases da Educação n 9394/96 estabelece as diretrizes e bases da educação nacional e institui o Plano Nacional de Educação, com diretrizes e metas para a década seguinte. Com o objetivo de combater a repetência e dar ênfase na melhoria da qualidade de ensino, o artigo 24, inciso V, alíneas b e c propõem estratégias de correção de fluxo escolar.

5. Conjunto de diretrizes de política em processo contínuo de atualização e negociação, cujo horizonte deverá coincidir com a reconstrução do sistema nacional de educação básica - Plano Decenal de Educação para Todos, (BRASIL, 1993, p. 15). 
O conjunto dessas leis e planos, no Brasil, acompanhou a orientação mundial de reorganização da política neoliberal, apresentando como princípio as reformas administrativas e gerenciais das escolas, criando mecanismos de regulação da eficiência, da produtividade e da eficácia da educação.

\section{CONTEXTO DA PRODUÇÃO DO TEXTO}

O contexto da produção do texto, segundo Ball (1992) apud Mainardes (2006, p. 52), se constitui pelos "textos políticos e textos legais oficiais" que dão forma à política proposta, e são as bases iniciais para que as políticas sejam colocadas em prática.

Ao analisar a Proposta Curricular da Educação Física de Minas Gerais, denominada Conteúdo Básico Comum ${ }^{6}$ (CBC - 2008), verificamos que foram introduzidos nesta proposta os quatro pilares da Educação citados no relatório da UNESCO - Educação: um tesouro a descobrir - presidido por Jacques Delors ( 1998). Ao tratar do tema "finalidades da Educação Física", o documento do CBC destaca que "discutir a importância da Educação Física à luz da proposta da UNESCO para a educação no século XXI permitiu-nos redimensionar suas finalidades a partir de quatro pilares: aprender a conhecer e a perceber; aprender a conviver; aprender a viver e aprender a ser" (MINAS GERAIS, 2008, p. I6). O documento anuncia, em tom prospectivo, que no Século $X X \mid$ estaremos expostos a dilemas e incertezas, sendo necessário assinalar novos objetivos e mudanças na ideia que se tem da utilidade da educação.

O projeto Acelerar para Vencer foi implantado pela Secretaria Estadual de Educação de Minas Gerais (SEE-MG) na administração do governador Aécio Neves e da Secretária de Educação Vanessa Guimarães Pinto. Através da resolução SEE n 1033, de 17 de janeiro de 2008, dispõe sobre a implantação do Projeto de Aceleração da Aprendizagem "Acelerar para Vencer", para alunos do ensino fundamental da rede estadual de ensino de Minas Gerais; propõe como objetivos:
a) aumentar a proficiência média dos alunos do Ensino Fundamental;
b) reduzir, progressivamente, as taxas de distorção idade/ano de escolaridade;
c) promover a aquisição de competências e habilidades básicas, indispensáveis ao sucesso do aluno na vida e na escola;
d) fortalecer a autoestima dos alunos, inserindo-os no ano escolar adequado para o prosseguimento dos estudos;

\footnotetext{
6. Resolução n 666/2005 - O CBC é uma proposta curricular para todos os componentes curriculares, que tem como objetivo estabelecer os conhecimentos, as habilidades e competências a serem adquiridas pelo aluno na educação básica, bem como as metas a serem alcançadas pelo professor a cada ano.
} 
e) oferecer um currículo diversificado, como forma de garantir a todos um patamar comum de qualidade na conclusão de estudos. (MINAS GERAIS, 2008, p. 20).

A primeira região atendida em 2008 foi o norte de Minas, onde se concentra o maior índice de distorção idade/ano de escolaridade. No ano seguinte, o PAV foi implantado nas demais regiões do estado. $O$ projeto destina-se a alunos das séries iniciais e finais do ensino fundamental, estruturado, preferencialmente, em turmas de 25 alunos, considerando sempre a realidade e as necessidades da escola. Estes alunos são considerados como incapazes em função das sucessivas repetências, e acumulam histórias de fracasso escolar e de autoestima fragilizada; por isso, necessitam de um projeto específico que Ihes possibilite superar as dificuldades e recuperar o tempo perdido.

A meta da proposta é oferecer uma opção de ensino baseada na pedagogia de projetos, ${ }^{7}$ organizando os conhecimentos escolares com mediação do professor, para promover uma aprendizagem mais ativa, que desenvolva habilidades de interação, de resolução de problemas e desafios, permitindo articular estratégia de aprendizagem eficiente e significativa. $\bigcirc$ trabalho com projetos possibilita uma aprendizagem colaborativa, na qual dois ou mais alunos, trabalhando em grupos, com objetivos compartilhados, auxiliam-se mutuamente na construção do conhecimento.

A metodologia de trabalho do PAV supõe um ensino que esteja "estruturado em pequenos projetos, com trabalhos em grupos independentes, numa abordagem interdisciplinar, dentro do conceito de aprendizagem colaborativa" 8 (PAV, 2008, p.8). Devem-se trabalhar as habilidades para que os alunos sejam capazes de produzir o próprio conhecimento, com ênfase na autonomia e na independência intelectual e instrumentalizar-se para compreender os acontecimentos e as relações sociais, de forma reflexiva e crítica.

\section{CONTEXTO DA PRÁTICA - ANALISANDO O PLANEJAMENTO CURRICULAR DA EDUCAÇÃO FÍSICA: DILEMAS E PERSPECTIVAS}

Trataremos aqui o contexto da prática, analisando dados sobre planejamento, com foco nas ações pedagógicas do professor com relação à implementação do PAV.

O contexto da prática é a arena política em que os textos estão sujeitos a interpretações e recriações diferentes, em cada unidade escolar. Segundo Ball ( 1992)

7. Pedagogia de projetos é uma proposição secular. Contrapondo-se à pedagogia tradicional e buscando uma proposta progressista, Dewey (1915) e Killpatrick (1918) apud Behrens e Zem (2007) postulam, na pedagogia de projetos, a possibilidade de uma pedagogia aberta, em que o aluno é o ator da sua formação por meio de aprendizagens concretas e significativas.

8. A aprendizagem colaborativa, segundo Dillenbourg (1999) apud Torres e Irala (2007, p. 70), é uma situação de aprendizagem na qual duas ou mais pessoas aprendem ou tentam aprender algo juntas. 
apud Mainardes (2006, p. 53), "os profissionais que atuam no contexto da prática não enfrentam os textos políticos como leitores ingênuos, eles os vêem com suas histórias, experiências, valores e propósitos".

No caso mineiro, temos evidência de que os professores, por diferentes referências, possuem clareza sobre o processo de implementação das políticas de educação. Observe-se, por exemplo, a leitura que o professor realiza no conteúdo do contexto da influência da política do PAV:

\begin{abstract}
Os nossos governantes, de tempos em tempos, resolvem fazer uns acertos com o Banco Mundial para arrecadação de verba e implantam em nosso país projetos que são realizados no primeiro mundo; nós tivemos uma experiência, alguns anos atrás, com o Projeto Acertando o Passo, depois veio a Progressão Continuada e tudo isso está contribuindo para o desastre da educação (fragmentos da entrevista).
\end{abstract}

Ao analisarmos como o PAV é executado nas aulas de Educação Física e como o professor interpreta o texto da política e organiza sua prática pedagógica, percebemos aproximação com o que Ball (1992) apud Mainardes e Marcondes (2009, p. 305) relata sobre a efetivação de uma política na prática. Segundo o autor, esta pode ser considerada "quase como uma peça teatral". Temos a obra a ser encenada e o seu texto pode ser alterado, invertido ou suprimido, pode permanecer por pouco ou muito tempo em cartaz e o poder de criação e interpretação depende do momento da sua execução (MOLINA, 20I0).

O que constatamos, ao observar a prática, é um esforço do professor para executar o planejamento em sua totalidade; embora sem os recursos materiais, este busca acertar um conjunto de ações para sistematizar sua prática em função do planejamento a ser cumprindo e da possibilidade do aluno se apropriar desse conhecimento específico. Esta realidade está registrada na observação de campo, apresentada a seguir.

Professor, durante a reunião pedagógica com a supervisora, explica que no seu planejamento contempla o conteúdo de handebol na turma do PAV; entretanto, ao examinar o material, verifica que não tem bolas de handebol. Como havia combinado com os alunos, e não quer voltar atrás, utiliza algumas bolas de borracha e organiza pequenos jogos para poder vivenciar o esporte. $O$ professor explica aos alunos que gostaria de desenvolver o esporte do handebol, porém, sem material, teria que adaptar o jogo com o que tinham na escola, algumas bolas de borracha (Diário de campo, 24-08-2010).

No planejamento da Educação Física referente ao PAV $2^{9}\left(8^{\circ}\right.$ e $9^{\circ}$ anos do Ensino Fundamental) da escola investigada, constatamos que o objetivo geral

9. O PAV I é destinado à recuperação do $6^{\circ}$ e $7^{\circ}$ anos do Ensino Fundamental; o PAV 2 é destinado à recuperação do $8^{\circ}$ e $9^{\circ}$ anos do Ensino Fundamental. 
e o específico contemplam a proposta do CBC, sendo os objetivos específicos a cópia das finalidades dos princípios do "aprender a aprender". Os conteúdos são apresentados em quatro eixos: esporte, jogos e brincadeiras, ginásticas, e danças e expressões rítmicas, organizados em tópicos e habilidades. Ao analisar tópicos e habilidades no planejamento, constatamos que os conteúdos: esporte, jogos e brincadeiras e ginástica não apresentam a orientação específica do PAV. Estes são recortes de textos da proposta do $\mathrm{CBC}$ do ensino fundamental, mesclados com o ensino médio. No eixo danças e expressões rítmicas, encontramos as orientações do PAV contempladas na sua totalidade, concomitantemente com o CBC.

O desenvolvimento destes conteúdos na prática pedagógica revela algumas contradições pelo fato de o professor desconhecer as orientações gerais desta política. As atividades desenvolvidas, quando se aproximam da proposta, estão relacionadas à intuição e concepção do professor, mais do que ao entendimento e orientação para a implementação da política. Ou seja, o texto foi modificado e recriado no contexto da prática, e o professor o executa segundo princípios estabelecidos por ele mesmo:

Com relação ao planejamento, foi uma exigência que se fizesse um plano especial para o PAV. Eu não. Fiz o mesmo planejamento do ensino regular. A forma como eu trabalho com eles não é diferenciada, justamente porque são alunos do PAV (...) a única coisa que eu faço de diferente é que às vezes você tem que fazer um trabalho individual, se dedicar um pouco mais ao aluno que tem defasagem na escola, mas o planejamento é o mesmo (fragmento de entrevista).

Conforme referimos antes, a orientação metodológica do PAV é que se trabalhe com a pedagogia de projetos, com ações que valorizem as experiências trazidas pelos alunos e os conteúdos a serem ensinados. Agindo nesta linha, o professor problematiza e inter-relaciona o que o aluno já sabe, para ampliar e aprofundar os conhecimentos. Essa orientação não foi identificada nas atividades nem no planejamento, e o professor revela que

Desconheço qualquer orientação específica na disciplina de Educação Física no PAV, sendo que no início foi me cobrado, pela supervisão escolar, apenas o meu planejamento anual e bimestral, conforme as normas da escola (fragmentos da entrevista).

O registro acima indica que a releitura da política não se verifica apenas com o professor, mas também com os supervisores e todos os que vão lendo o texto, mas não participaram de sua construção. $\bigcirc$ contexto da prática, na pedagogia de projetos, pode indicar a falta de conhecimento do professor sobre o tema, ou a dificuldade de traduzir para seu planejamento ações dessa perspectiva pedagógica, em função da inexistência ou da pouca formação específica dos atores da cena pedagógica. 
No item avaliação, a descrição da forma como os alunos serão avaliados contempla as orientações do PAV, com a utilização de diferentes instrumentos de avaliação, como trabalhos e pesquisas individuais e coletivas e a participação nas aulas. Entretanto, não fica claro que a verificação do progresso no processo de ensino-aprendizagem ocorre a partir de parâmetros de comparação interindividual, com foco no aluno.

\section{CONSIDERAÇÕES FINAIS}

Sendo este artigo um recorte de estudo maior, de metodologia referente a estudo de caso, não é possível, e tampouco temos a pretensão, de generalizar seus resultados. As análises aqui realizadas podem colaborar no entendimento do componente curricular educação física em projetos dessa natureza, considerando as particularidades de cada cotidiano, na reflexão de projetos de correção de fluxo.

As políticas públicas analisadas neste estudo, referidas nas pesquisas de $\mathrm{Mi}$ randa (2002), Espíndola (2003), Souza (2007), Coimbra (2008) e Moraes (2009), comprovam que estas se concentram na recuperação da defasagem idade-série e que os alunos retomam sua trajetória escolar. As demais facetas apresentadas no projeto, como, por exemplo, a formação humana integral, tornam-se secundárias diante da prioridade da redução dos indicadores oficiais do binômio reprovação e evasão escolar.

A implementação do PAV é influenciada pelas políticas neoliberais para regular o fluxo escolar e diminuir os índices de repetência e evasão escolar. Desconsideram-se as questões relativas à gestão da escola, à organização pedagógica, à estrutura física, à realidade dos alunos e à sua própria formação.

No planejamento da educação física o professor possui conhecimento superficial, que não ajuda na organização do planejamento e na sistematização de sua prática pedagógica, segundo os propósitos estabelecidos pelo PAV. Embora seu planejamento contemple alguns dos princípios do PAV e do CBC da Educação Física, tais princípios aparecem como recortes e paráfrases desses dois documentos.

Verifica-se o esforço do professor em organizar o planejamento para contemplar as diretrizes de um projeto de correção de fluxo e em construir o saber escolar específico da área proposto no CBC articulando com o PAV. Identificamos também o desafio de abordar os conteúdos da área em projetos dessa natureza, quer nos conhecimentos específicos, quer no processo de inserção da educação física nos contextos das diferentes políticas educacionais. 


\section{Curriculum planning of Physical Education in project for students with age-grade distortions}

ABSTRACT: In Minas Gerais, a project known as Accelerate to Win is being carried out with the purpose of offering strategies for pedagogical intervention towards students with age-grade distortions. In this article, we discuss the planning of physical education curriculum in order to identify its organization and teaching practices of this project. The analytical framework used to understand this educational policy rests on the policy cycle of Stephen Ball and Richard Bowe ( 1992) apud Mainardes (2006). The corpus is constituted with documents of curricular design and teacher planning. We conclude that planning has not actually expressed how Physical Education contributes to the development of a project that aims to reduce school inequalities. KEYWORDS: Educational policy; physical education; accelerate to win; curriculum planning.

\section{Planificación curricular de la educación física del proyecto de corrección edad/grado en la escuela}

RESUMEN: En Minas Gerais, el proyecto Acelerar para Vencer busca ofrecer estrategias de intervención pedagógica para alumnos con baja relación edad/grado. Analizamos criticamente la planificación curricular de la Educación Física para identificar su organización y practicas pedagógicas en este proyecto. El referencial analítico para la comprensión de esta política educativa fundamentase en el ciclo de políticas educativas de Stephen Ball y Richard Bowe (1992) apud Mainardes (2006). El corpus se constituye de los documentos de las orientaciones curriculares del proyecto y de la planificación de los profesores. Concluimos que la planificación todavía no expresa como la Educación Física contribuye en el desarrollo de un proyecto que pretende disminuir las desigualdades escolares.

PALABRAS CLAVE: Política educativa; educación física; proyecto aceleración del aprendizaje, planificación curricular.

\section{REFERÊNCIAS}

ANDRÉ, M. E. D. A. Etnografia da prática escolar. Campinas: Papirus, 1995

BARDIN, L. Análise de conteúdo. Lisboa: Edições 70, 2009.

BEHRENS, M. A.; ZEM, R. A. M. S. Metodologia de projetos: o processo de aprender a aprender. In: TORRES, P. L. (Org.). Algumas vias para entretecer o pensar e o agir. Curitiba: SENAR, 2007. p. 38-65.

BRASIL. Ministério da Educação. Lei n. 9394, de 20 de dezembro de 1996. Diretrizes e Bases da Educação Nacional. Diário Oficial da União, Brasília, v. I34, n. 248, p. 833- 84I . 1996.

BRASIL. Ministério da Educação e do Desporto. Secretaria de Educação Fundamental. Plano Decenal de Educação para Todos. Brasília, 1993. 
COIMBRA. S. R. S. Reprovação e interrupção escolar: contribuições para o debate a partir da análise do projeto classes de aceleração. 2008. 206 f. Tese (Doutorado em Educação) Universidade Federal Santa Catarina, Santa Catarina, 2008.

DELORS, J. et al. Educação: um tesouro a descobrir. Relatório para a UNESCO da Comissão Internacional sobre Educação para o Século XXI. Brasília: Ministério da Educação e Cultura: UNESCO, 1998.

ESPÍNDOLA, C. A. Programa de aceleração de estudos em Minas Gerais: o que mudou na vida dos egressos. 2003. 12 I f. Dissertação (Mestrado em Educação) - Universidade Católica de Petrópolis, Petrópolis, 2003.

LATORRE, A.; ARNAL, J.; RINCÓN, D. Bases metodológicas de la investigación educativa. Barcelona: Hurtado, 1997.

MAINARDES, J. Abordagem do ciclo de políticas: uma contribuição para a análise de políticas educacionais. Revista Educação e Sociedade, Campinas, v. 27, n. 94, p. 47-69, jan. 2006. Disponível em: http://www.scielo.br>. Acesso em: 20 out. 2009.

.; MARCONDES, M. I. Entrevista com Stephen Ball: um diálogo sobre justiça social, pesquisa e política educacional. Educação e Sociedade, Campinas, v. 30, n. I06, p. 303-3 I 8 , jan./abr. 2009. Disponível em: <http://wnw.cedes.unicamp.br>. Acesso em: 20 out. 2009

MINAS GERAIS. Secretaria de Educação. Institui o Projeto Acertando o Passo, implantando a estratégia pedagógica de aceleração de estudos, destinada a alunos do $2^{\circ}$ Ciclo do Ensino Fundamental, noturno, fora da faixa etária, em escolas da Rede Estadual de Ensino. Resolução Conselho Estadual de Educação n. 8287, 09 de janeiro de 1998. Diário Oficial de Minas Gerais, n. 266, p. 31-33, fev. 1998.

Institui o Projeto Travessia, implantando a estratégia pedagógica de aceleração de estudos, destinada a alunos do $1{ }^{\circ}$ Ciclo do Ensino Fundamental, noturno, fora da faixa etária, em escolas da Rede Estadual de Ensino. Resolução Conselho Estadual de Educação n. 9298, 02 de março de 1998. Diário Oficial de Minas Gerais, n. 267, p. 13- 14, mar. 1998.

MINAS GERAIS. Secretaria de Educação. Institui o Projeto a caminho da cidadania, implantando a estratégia pedagógica de aceleração de estudos, destinada aos alunos do ensino médio, noturno, fora da faixa etária, em escolas da Rede Estadual de Ensino. Resolução Conselho Estadual de Educação n. 9.433, 30 de junho de 1998. Diário Oficial de Minas Gerais, n. 272, p. 12-24, ago. 1998.

Dispõe sobre a implantação do Projeto de Aceleração da Aprendizagem: "Acelerar para Vencer", para alunos do ensino fundamental da rede estadual de ensino de Minas Gerais. Resolução n. 1033, 17 de janeiro de 2008. Disponível em: https://www. educacao.mg.gov.br/webjzf/index.php/resolucoessee. Acesso em: 02 mar. 2010.

Estabelece os conteúdos básicos comuns: CBCs a serem obrigatoriamente ensinados pelas unidades de ensino estaduais que oferecem as séries finais do ensino fundamental e o ensino médio Resolução n. 666/2005, 07 de abril de 2005. Diário Oficial de Minas Gerais, Imprensa Oficial, Executivo, 08 abr. 2005. Disponível em: https://www.educacao. mg.gov.br/webjzf/index.php/resolucoessee. Acesso em: 02 mar. 2010. 
Projeto estruturador: Aceleração da aprendizagem do norte de Minas, Jequitinhonha, Mucuri e Rio Doce. Documento base. Belo Horizonte, 2008. Disponível em: http://crv.educacao.mg.gov.br. Acesso em: 02 mar. 2010.

Conteúdos básicos comuns/Educação Física: ensino fundamental e médio. Belo Horizonte, 2008. Disponível em: http://crv.educacao.mg.gov.br/. Acesso em: 02 mar. 2010.

Guia de orientação curricular. Conteúdos básicos do projeto acelerar para vencer. Ensino fundamental do $6^{\circ}$ ao $9^{\circ}$ ano. Belo Horizonte, 2009. Disponível em: http:// crv.educacao.mg.gov.br. Acesso em 2 mar. 2010.

MINAYO, M. C. de S. O desafio do conhecimento: pesquisa qualitativa em saúde. São Paulo: Hucitec; Rio de Janeiro: Abrasco, 2006.

MIRANDA, F. A. Programas de aceleração de estudos: uma análise de resultados de PROEB 2000. 2002. 66 f. Dissertação (Mestrado em Educação) - Universidade Federal de Juiz de Fora, Juiz de Fora, 2002.

MOLINA, R. K. Formação em educação física: políticas, ingerências e efeitos. In: TERRA, D. V; SOUZA JR., M. Formação em Educação Física \& ciências do esporte: política e cotidiano. São Paulo: Hucitec; Goiânia: CBCE, 20 I0. p. 75-91. (Paidéia n. 16).

MORAES, A. F. de. Rastros da singularidade no dizer do aluno do Acelera: marcas da constituição subjetiva e os (im) possíveis efeitos do (des) colamento significante. 2009. 198 f. Dissertação (Mestrado) - Universidade Federal de Uberlândia, Uberlândia, 2009.

SOUZA, M. F. M. Política de correção de fluxo: um estudo avaliativo do Programa de Aceleração da Aprendizagem em Santarém-Pará. 2007. 173 f. Tese (Doutorado em Educação) - Universidade Estadual Paulista, Araraquara, 2007.

TOMMASI, L. Financiamentos do Banco Mundial no setor educacional brasileiro: os projetos em fase de implementação. In: TOMMASI, L.; WARDE, M. ..; HADDAD, S. O Banco Mundial e as políticas educacionais. São Paulo: Cortez, 1998. p. 195-215

TORRES, P. L.; IRALA, E. A. F. Aprendizagem colaborativa. In: TORRES, P. L. Algumas vias para entretecer o pensar e o agir. Curitiba: SENAR, 2007. p. 66-91.

Recebido: 21 mai. 2010 Aprovado: 01 nov. 2011

Endereço para correspondência: Alessandra Cristina Raimundo Rua Dionísio Herthal, $69 \mathrm{apt}^{\circ}$. 1005 Bloco 03

Bairro: Santa Rosa Niterói - RJ CEP:24240-020 